\title{
Reflexões sobre o paradigma da economia ecológica para a gestão ambiental MAURÍCIO FUKS
}

“Tendo o homem expandindo seus poderes biológicos através da produção de artefatos industriais, ele se tornou, ipso facto, não apenas dependente de uma fonte muito escassa de suporte a vida, mas também viciado nos luxos industriais.”

(Georgescu-Roegen, 1993, p.86)

\section{Introdução: A relativa ausência da economia ecológica na área de Gestão Ambiental}

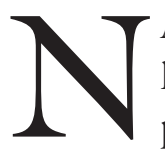

AS ÚLTIMAS décadas, em razão dos graves problemas ambientais de poluição e de exaustão de recursos, tem-se notado uma demanda crescente por profissionais na área de Gestão Ambiental. O mundo acadêmico está ciente dessa tendência, como pode ser observado pelo número cada vez maior de cursos e pela retórica otimista sobre oportunidades de carreira, especialmente nos países desenvolvidos. Entretanto, o número de instituições que ensinam Economia Ecológica e a demanda por esses profissionais ainda são limitados (Viederman, 1994). ${ }^{1}$ O primeiro objetivo deste estudo é precisamente chamar a atenção para o hiato entre o crescimento significativo da área de Gestão Ambiental e uma perceptível ausência de conhecimento sobre os conceitos e questões centrais da economia ecológica. Visando especialmente aqueles que se voltam para gestão ambiental, almeja-se resumir o mapa da realidade, ainda pouco conhecido, que o novo paradigma da economia ecológica propõe em relação à sustentabilidade. Tal síntese destacará a visão singular que essa escola de pensamento possui do processo econômico (incluindo o que se refere ao papel das empresas), da base de recursos que a humanidade dispõe e da crucial questão da escala do sistema econômico global.

Este artigo advogará que tal paradigma de sustentabilidade contrasta consideravelmente com a retórica comum da gestão ambiental e que muitos profissionais desse campo, caso prescindam de conhecimentos de economia ecológica, poderão permanecer num estado de ingenuidade otimista em relação ao papel e comportamento das empresas, bem como em relação à natureza do processo econômico. Como exemplo sintomático dessa visão superficial, destacar-se-á a frequente tendência da literatura de gestão ambiental em focar políticas "win-win". ${ }^{2}$ Por fim, o texto conclui com a tese de que o contato travado com as 
ideias centrais da economia ecológica é capaz de alterar a compreensão do conceito de sustentabilidade naqueles que se voltam para gestão ambiental.

\section{Economia ecológica:}

\section{um novo paradigma econômico para sustentabilidade}

Georgescu-Roegen (1971) salientou que, de acordo com a primeira lei da termodinâmica, não podemos criar nem destruir matéria ou energia (Princípio da Conservação da Matéria-Energia), e consequentemente indagou: o que faz então o processo econômico? A resposta é absorver, transformar qualitativamente a baixa entropia e lançá-la fora do sistema econômico na forma de alta entropia. ${ }^{3}$ Ou seja, o sistema econômico é um subsistema do ecossistema global finito, dependendo dele tanto para extrair baixa entropia quanto para, ao usá-la, despejá-la na forma de alta entropia (Figura 1).

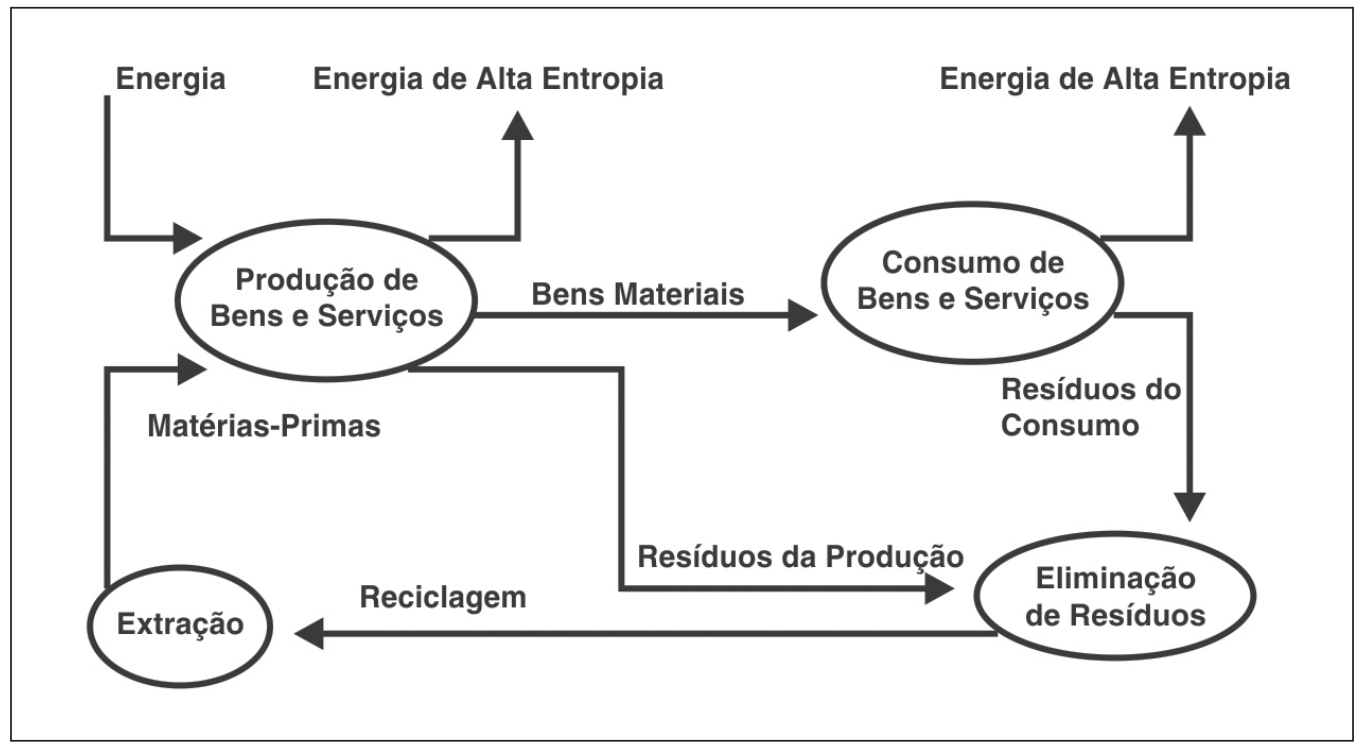

Fonte: Ayres \& Nair (1984).

Figura 1 - Fluxos de matéria e energia pelo sistema econômico.

Tal perspectiva entrópica do processo econômico é radicalmente oposta ao mecanicismo da teoria econômica padrão. Ao contrário da visão newtoniana, em que um sistema apresenta reversibilidade temporal, permanecendo idêntico; a segunda lei da entropia indica uma mudança qualitativa unidirecional e irrevogável: a magnitude de energia não disponível de um sistema fechado aumenta continuamente. Para diminuirmos a entropia de um sistema, necessitamos obter energia do exterior, o que implica aumentar o déficit entrópico global.

Organismos vivos não são exceção à segunda lei da termodinâmica, pois sobrevivem absorvendo baixa entropia do meio ambiente para compensar o aumento de entropia a que estão sujeitos. Desse modo, embora evitem temporariamente a sua dissipação, seres vivos elevam a entropia do sistema como um 
todo, isto é, do meio ambiente onde estão inseridos. Ou seja, a presença de vida acelera o processo entrópico (Georgescu-Roegen, 1971, 1993).

Adicionalmente, nosso comportamento difere da quase totalidade dos demais seres vivos, pois esses praticamente sobrevivem da baixa entropia ao seu arredor. Com raras exceções, as demais espécies utilizam apenas instrumentos endossomáticos; em outras palavras, herdados geneticamente (por exemplo, pernas, patas, asas). A humanidade evoluiu a ponto de usar instrumentos exossomáticos, ou seja, que transcendem o corpo (Georgescu-Roegen, 1993). Segundo Georgescu-Roegen, a evolução exossomática gerou os conflitos sociais que caracterizam a espécie humana, o que o levou a questionar se estaríamos viciados em tais instrumentos, e a concluir que, por causa deles, o problema de nossa sobrevivência se diferenciou do das demais espécies, tornando-se uma questão bioeconômica.

A visão entrópica do processo econômico é igualmente contundente em relação ao papel das empresas. Essas, não raro, fabricam produtos mais complexos que os insumos utilizados para sua fabricação. Isso poderia gerar a ilusão de uma inversão do processo entrópico, já que os inputs são menos complexos que o output. Entretanto, para estruturar seus produtos, empresas requerem energia, aumentando a entropia do sistema nas quais estão inseridas, ou seja, do meio ambiente. Entropicamente, o custo de qualquer atividade econômica (ou biológica) é sempre superior ao do seu produto. Produzir, mesmo de modo ecoeficiente, acelera o déficit entrópico global.

Georgescu-Roegen conclui que a luta econômica do homem é um esforço pela busca de baixa entropia, e que a nossa extração de recursos deixa marcas na história, sendo um elemento crítico de longo prazo para o destino da humanidade. Seria por causa da escassez particular da baixa entropia, de sua quantidade limitada e irreversibilidade, que desenvolvemos invenções que visam "ceifar" baixa entropia do meio ambiente (ibidem).

A perspectiva entrópica do processo econômico levou Georgescu-Roegen $(1993,1994)$ a distinguir as assimetrias das fontes de riqueza da humanidade, bem como a elaborar o seu plano bioeconômico. Os pontos a seguir resumem a sua análise:

- Temos duas fontes distintas de energia: (1) o estoque de energia livre contida nos depósitos minerais e (2) o fluxo de radiação solar interceptado pela Terra. A radiação solar, que propicia a fotossíntese, é a maior fonte de energia para toda a vida.

- O estoque terrestre de baixa entropia é mínimo em comparação com o fluxo de energia solar. Colocado de outra forma, há uma diferença astronômica entre a quantidade de energia do fluxo solar vis-à-vis o estoque de energia terrestre.

- Temos controle quase total sobre o estoque terrestre, e dada a irrevogabilidade da degradação entrópica, é concebível exauri-lo em relativamente 
pouco tempo. Todavia, não controlamos o fluxo de energia solar, tampouco podemos utilizar o fluxo futuro. Em outras palavras, a geração atual não pode alterar a parcela de energia solar que caberá às gerações futuras.

- Apenas o estoque terrestre nos fornece baixa entropia na forma de matéria, pois não há procedimento viável para transformarmos energia em matéria. Essa fonte específica de baixa entropia é requerida para produzir nossos artefatos.

- Para uso industrial, a energia solar possui uma desvantagem em relação às fontes terrestres: sua baixa intensidade, se comparada ao alto grau de concentração das fontes terrestres. Essa dificuldade, entretanto, pode ser ultrapassada.

- Somos a única espécie que se tornou dependente dos instrumentos exossomáticos, fato que não somente gerou nossa imensa econosfera, como também levou à extinção de inúmeras espécies.

Infelizmente, gerações futuras não têm voz e, tendo em vista essas circunstâncias, a principal mensagem de Georgescu-Roegen em relação a pesquisas em prol da sustentabilidade é evidente: ao invés de buscarmos meios mais eficientes de usar nossos recursos terrestres, devemos concentrar esforços aprimorando o uso direto da energia solar. Cada passo que nos aproxime de uma economia baseada na energia solar significa, potencialmente, uma redução do monopólio dos recursos terrestres pela geração presente sobre as gerações futuras.

Por essa óptica, pode-se argumentar que a extração acelerada de recursos terrestres necessários para o desenvolvimento, especialmente durante o século $\mathrm{XX}$, foi um péssimo sinal para as gerações futuras. Georgescu-Roegen questiona até mesmo a mecanização da agricultura, processo necessário para expansão populacional do século passado. Contudo, a mecanização exigiu intenso uso de recursos terrestres (por exemplo, tratores e fertilizantes), em vez do uso da tração animal e do adubo natural. Consequentemente, essa dinâmica, embora inevitável no presente, seria antieconômica no longo prazo.

Esse setor, contudo, seria apenas um exemplo. Levando-se em conta a atual tendência, nossa sobrevivência dependerá crescentemente dos recursos terrestres não renováveis, nossa fonte mais escassa de baixa entropia. $\mathrm{O}$ principal problema da humanidade será a redução do estoque terrestre de baixa entropia, pois dada a desproporção entre o fluxo solar e o estoque terrestre, mesmo "com o uso muito parcimonioso do estoque, a fase industrial da evolução do homem terminará muito antes de nosso Sol cessar de brilhar" (Georgescu-Roegen, 1993, p.85). Diante dessa dinâmica, torna-se eticamente questionável o uso dessa fonte para produção de objetos supérfluos, já que significará menos enxadas e arados no futuro. A pergunta-chave é se estaríamos dispostos a deixar de lado tais luxos para auxiliar seres humanos do futuro longínquo.

O resumo anterior é fundamental para compreendermos o plano bioeconômico de Georgescu-Roegen (1993b, p.104): 
- Cessar todas as guerras e proibir o uso de quaisquer recursos para produção de instrumentos de guerra. Tais recursos deveriam ser direcionados para ajuda internacional, isto é, usados para fins de equidade intrageracional.

- Com esses recursos, as nações desenvolvidas devem ajudar as demais a atingirem um bom padrão de vida. Observe que isso não equivale a uma vida de luxo ou de consumo ostensivo.

- A população planetária deve gradualmente reduzir-se a um patamar que permita o uso de métodos orgânicos de agricultura (de-growth).

- Desperdícios da energia gerada pelas fontes terrestres devem ser evitados e, se necessário, regulamentados.

- Renúncia ao consumo ostensivo e supérfluo. Sem a demanda por tais bens, a oferta cessará.

- O abandono de um modo de vida centrado em modismos ("fashion").

- Elevação do tempo de durabilidade dos bens, considerando até mesmo designs que facilitem o reparo.

- Abandono do modo de vida baseado na síndrome do aparelho de barbear. $^{4}$

Kenneth Boulding, outro pensador de imensa influência para a economia ecológica, também foi enfático quanto à necessidade de transformação no comportamento econômico da humanidade. ${ }^{5}$ Em seu livro The meaning of the Twentieth Century, Boulding (1964), argumenta que o século XX representou uma grande transição para a humanidade, sendo estes alguns dos sintomas: i) elevadíssima taxa de extração de recursos pelo sistema econômico moderno; ii) elevada magnitude da população planetária; iii) extraordinária capacidade de recuperação das sociedades modernas (por exemplo, Alemanha e Japão no pós-guerra); iv) ampliação da antiga lealdade familiar para o Estado nacional, ou até mesmo para o mundo como um todo; v) nas sociedades avançadas contemporâneas as taxas de natalidade decresceram, o que foi positivo e necessário, em razão da elevação da expectativa de vida e a queda da mortalidade infantil; vi) em relação à primeira grande transição, do Paleolítico para o Neolítico, essa apresenta um certo grau de uniformidade no planeta como um todo. ${ }^{6}$

Tal transição, entretanto, não levará, necessariamente, a avanços éticos ou morais, e tampouco podemos afirmar que ela seja inevitável. Boulding advoga a tese de que há uma série de armadilhas, como a da população, da guerra e a entrópica. Em relação a esta última armadilha, a possibilidade de um desfecho trágico se daria em razão da rápida exaustão dos recursos não renováveis. Nesse caso, nosso alto padrão de vida, bem como a explosão populacional do século XX seriam um episódio breve na história da humanidade: "É possível que em mil anos... nossos descendentes herdem uma Terra devastada e exaurida... O homem tenderá a ser, então, pressionado a uma sociedade de baixo padrão de vida"7 (Boulding, 1964, p.150). 
Boulding, porém, conclui que outro desfecho também é possível, de modo que o atual período pode ser percebido como uma oportunidade onde o capital geológico acumulado é usado com vistas a produzir conhecimento suficiente para que a humanidade mantenha um padrão de vida elevado sem exauri-lo. Essa incerteza, evidentemente, leva-o a desqualificar o dispêndio em consumo fútil e o desperdício de recursos para produção de instrumentos de guerra. Pois, caso haja apenas uma pequena probabilidade de atingirmos tal conhecimento, todos os esforços devem ser direcionados à obtenção de tecnologia que mantenha as fontes de recursos e funcione a base do fluxo de energia solar (Boulding, 1993; Fuks, 1992, 1994)

Em seu texto mais renomado, Boulding (1993) indica que estaríamos passando por um longo período de transição em relação à imagem que possuímos do meio ambiente. Até a primeira metade do século XX, tínhamos uma percepção da Terra como espaço e recursos ilimitados (essa seria a economia do cowboy). Ainda estaríamos nos adaptando à noção da Terra como um sistema fechado, onde não entra ou sai matéria, permitindo apenas a troca de energia. Destaca-se que, em tal sistema, o output de todas as partes está conectado aos inputs de outras partes. ${ }^{8} \mathrm{Na}$ famosa metáfora da espaçonave Terra, nosso planeta é uma nave espacial usada para uma longa viagem (a sustentabilidade), sem reservatórios ilimitados (para extrair baixa entropia ou lançar alta entropia) e com uma quantidade limitada de recursos incluídos a bordo.

Nessa economia do astronauta, mesmo sem escapar da necessidade do fluxo de energia solar, os passageiros têm que estabelecer um sistema capaz de manter a base de recursos. Produção e consumo não são mais percebidos positivamente, o objetivo passa a ser o desenvolvimento de tecnologias que mantenham um dado estoque, fazendo menos uso do transumo, ou seja, com menos consumo e produção.

O leitor perceberá claramente a influência de Georgescu-Roeger e Boulding num excelente resumo dos pontos de consenso da economia ecológica realizado por Constanza et al. (1997, p.79): ${ }^{9}$

Quatro pontos de consenso da Economia Ecológica:

1. O planeta é um sistema termodinamicamente fechado, que não cresce do ponto-de-vista da matéria. O sistema econômico é um subsistema do ecossistema global, i.e., há um limite na magnitude de transumo que podemos obter e lançar no meio ambiente.

2. Respeitando os limites impostos por (1), a perspectiva de um futuro sustentável para o planeta, com alta qualidade de vida para todos, tanto seres humanos como de outras espécies.

3. O reconhecimento de que na análise de sistemas complexos como a Terra, em qualquer escala no tempo e espaço, a incerteza é grande e irreduzível, e certos processos são irreversíveis. Consequentemente, é necessário adotar uma postura de precaução. 
4. As instituições e o gerenciamento devem ser proativos, ao invés de reativos, resultando em políticas adaptativas e de implementação simples, baseadas numa sofisticada compreensão dos sistemas aos quais se referem e reconhecendo plenamente as incertezas subjacentes.

Considerando-se esses pontos de consenso, alguns autores advogam certas condições mínimas para sustentabilidade: i) a taxa de extração de um recurso renovável deve ser igual à sua taxa de regeneração; ii) a taxa de emissão de resíduos não deve ser superior à capacidade de assimilação do meio ambiente onde eles são despejados; iii) a taxa de extração dos recursos não renováveis deve ser equivalente à sua substituição por recursos renováveis (Daly, 1990b; Pearson \& Turner, 1994). Constanza et al. (1994) são igualmente claros quanto à necessidade de manutenção do capital natural total (CNT) em seu patamar corrente como condição mínima de sustentabilidade. Tal abordagem, denominada sustentabilidade forte, advém da complementaridade entre os capitais manufaturado e natural. ${ }^{10}$

Para esses autores, assim como para Boulding, a evolução humana passou de uma era na qual o capital gerado pelo ser humano (isto é, capital manufaturado) era o fator limitante para o desenvolvimento econômico, para uma era em que o capital natural restante se tornou o fator limitante. Com o aumento populacional e consequente expansão do sistema econômico global, passamos da uma economia do mundo vazio para a economia do mundo repleto. Ao contrário do passado, neste novo mundo a escala do sistema econômico global (população vezes o uso de recursos per capita), medida em unidades fisicas, torna-se uma questão critica para que a capacidade de suporte da biosfera não seja corroída ao longo do tempo (Constanza et al., 1997; Daly, 1990b, Daly et al., 2007).

Adicionalmente, as prioridades para a espécie humana são claras. A magnitude da escala do sistema econômico global, atualmente decidida pelos mercados, deve ser fruto de uma decisão social que contemple a capacidade de suporte da biosfera. Ou seja, eficiência alocativa não garante sustentabilidade. ${ }^{11}$ Satisfeita a condição primordial da escala do sistema econômico global, o sistema de preços pode ser usado para alocar recursos escassos. Os esquemas de cap-and-trade (por exemplo, Kyoto) servem como exemplo, já que determinam em primeiro lugar um limite físico máximo de emissão. Por fim, em relação à distribuição, almeja-se uma "divisão justa, ou ao menos que limite a desigualdade a um padrão aceitável” (Constanza et al., 1997, p.80-3; Cobb \& Daly, 1990; Daly 1990b).

\section{A preponderância da retórica otimista no discurso da gestão ambiental}

Pode-se argumentar que a contribuição central da economia ecológica, a inclusão e ênfase na questão da escala da econosfera (Cechin \& Eli da Veiga, 2010; Costanza et al., 1997, p.89), é um tema a ser tratado pelos governos, não cabendo às empresas incluí-lo nas suas tomadas de decisão. ${ }^{12}$ Mas, embora a magnitude do transumo demandado pelo sistema econômico global fuja do 
escopo das operações de qualquer corporação, não resta dúvida de que essa questão deve fazer parte central da formação (do conhecimento) de profissionais que se voltam para a gestão ambiental. Todavia, boa parte dessa literatura pouco reflete sobre a questão da escala do sistema, preferindo dar ênfase à premissa "onipresente em estudos de Gestão Ambiental, de que proteção ambiental tem que sempre gerar benefícios a empresa (pay off)" (Müller-Christ, 2011, p.48). Em vez de nos conscientizarmos de que o crescimento contínuo da econosfera não pode ser usado como panaceia para nossos problemas - pois hoje ocorre justo o contrário -, mergulhamos no mito da ubiquidade da "hipótese win-win".

Há, de fato, situações em que essa hipótese pode predominar e livros-texto, pesquisas acadêmicas e relatórios de gestão ambiental frequentemente se dedicam - e às vezes quase que exclusivamente - a reforçar essa visão como um mantra. ${ }^{13}$ Tampouco há dúvidas de que win-win outcomes, que geram melhoramentos de Pareto, devem ser explorados. Tal complementaridade entre lucro e proteção ambiental pode ocorrer em duas situações: via redução dos custos ou por meio da elevação do nível dos negócios (ibidem). A redução do uso de recursos materiais, energéticos e resíduos por unidade produzida seria exemplo de reduções de custo. Já a elevação do nível de negócios parte do princípio de que a proteção ambiental estaria associada a novos produtos e mercados (inovação); fortalecimento das marcas; redução do custo de capital (devido ao appeal adicional para os financiadores) e das responsabilidades jurídicas. Se a realidade é composta preponderantemente de situações "win-win", a implementação de Sistemas de Gestão Ambiental (SGA) por parte das empresas se torna evidentemente racional, até mesmo necessária, para expansão dos lucros. Sob essa óptica, não surpreende o fato de um típico livro-texto de gestão ambiental destacar que a implementação de SGA é uma mera questão de boa gestão (Blackburn, 2007, p.35). ${ }^{14}$

É, contudo, questionável a ênfase dada à "hipótese win-win", já que: (i) não raro, o fator mais importante na tomada de decisão por parte do gestor é a legislação; e (ii) havendo trade-off significativo entre proteção ambiental e lucro, a pressão por resultados financeiros de curto prazo provavelmente predominará (ibidem, p.31 e p.51). Adicionalmente, é impossível prever (ou medir) o quanto a complementaridade entre proteção socioambiental e lucro poderá nos auxiliar em termos da redução do transumo usado pela econosfera, pois nossa capacidade de suporte é, em última estância, o verdadeiro bottom-line. Podemos, por exemplo, obter grandes avanços em termos de ecoeficiência e, simultaneamente, elevar o transumo per capita mundial. Tendo em vista a elevação do padrão de vida dos países em desenvolvimento, não será surpreendente se esse for o desfecho nas próximas décadas. ${ }^{15}$

\section{Conclusão: a gestão ambiental não pode prescindir da economia ecológica}

$\mathrm{O}$ crescimento exponencial da econosfera durante o século XX transformou a relação que a humanidade possui com o meio ambiente. ${ }^{16}$ (Boulding, 
1964, 1993). Em cerca de 207 anos, de 1804 até 2011, passamos de um bilhão para sete bilhões de pessoas. Adiciona-se a esse fato a explosão de consumo que toma grande impulso, especialmente a partir da segunda metade do século XX nos países desenvolvidos e, mais recentemente, nos Brics (Brasil, Rússia, Índia e China). É evidente que essa dinâmica só foi possível em razão de um aumento exorbitante do transumo, isto é, do fluxo de baixa entropia que o sistema econômico requer para manter-se em funcionamento e que, com o seu uso, retorna aos sumidouros da natureza (environmental sinks) na forma de alta entropia. Como consequência, hoje convivemos tanto com a ameaça da exaustão quanto com os desequilíbrios dos sumidouros, que não conseguem mais absorver a quantidade de poluição emitida pelo sistema econômico global. ${ }^{17}$

Essa dinâmica, por sua vez, gerou uma série de reações, como um processo gradual de conscientização social em prol da sustentabilidade, especialmente nos últimos quarenta anos; o maior comprometimento em relação ao meio ambiente por parte das instituições políticas (em nível local, nacional e global) e a crescente aceitação por parte do setor empresarial de que a implementação de Sistemas de Gestão Ambiental (SGA) pode ser uma estratégia eficiente e cost-effective para lidar com os efeitos socioambientais negativos provocados pelas empresas em suas operações.

Permanecem, entretanto, sérias dúvidas acerca do grau de conscientização da humanidade, tanto em relação à preservação do meio ambiente quanto à justiça intra e intergeracional. Em particular, no que se refere ao atual tamanho da econosfera, alguns estudos recentes indicam que o sistema econômico global já se encontra além da escala sustentável (Arrow et al., 2004; Meadows et al., 2004; Wackernagel, 2008). Isso significa que ainda estamos distantes de realizar a transição da economia do cowboy para a do astronauta. De fato, desde a publicação do clássico texto de Boulding até o atual momento, a população do planeta dobrou; o consumo frívolo não foi refreado e a pobreza, a despeito de melhoras, permanece sendo um grave problema que atinge cerca de $20 \%-25 \%$ da população planetária. Tampouco, até o presente momento, desenvolvemos uma economia baseada no fluxo de energia solar, visando reduzir os efeitos do monopólio da geração presente, como desejavam Georgescu-Roegen e Boulding.

A economia ecológica salienta que escolhas difíceis são necessárias, pois não será possível resolver nossos problemas de escala e distribuição (intra e intergeracionais) meramente por meio dos mercados, menos ainda por meio do mito da ubiquidade da hipótese "win-win". Profissionais de gestão ambiental que tiverem oportunidade de aprender uma base de economia ecológica e atuarem no setor privado estarão diante de questões complexas - por exemplo: como investir para que nossas operações funcionem a base de energia solar; o quão essencial é o nosso produto (ou serviço); qual é a sua durabilidade, possibilidade de reutilização e de reciclagem; estamos minimizando o uso de matéria e de energia não renovável; ao utilizarmos recursos não renováveis usamos parte da 
receita para desenvolver substitutos renováveis; nossas operações danificam, de algum modo, o capital natural; incluímos em nossos cálculos todos os benefícios do capital natural; realizamos análise de ciclo de vida para avaliar os impactos ambientais de nossos produtos; subscrevemos a política de responsabilidade estendida do produtor visando internalizar impactos ambientais causados por nossos produtos?

Algumas dessas questões já são levantadas atualmente, mas não é mera coincidência que, em sua maioria, sejam aquelas que podem vir a se encaixar na hipótese "win-win". Contudo, somente de posse de uma base de conhecimento da economia ecológica percebe-se o processo econômico como um processo entrópico; as assimetrias na dotação dos recursos que nos são disponíveis e a questão crucial da escala da econosfera. Em suma, tem-se a visão de um novo paradigma que busca analisar a relação da humanidade com o meio ambiente visando à sustentabilidade de nosso planeta. Se esse for, de fato, o nosso objetivo primordial, aqueles que se voltam para gestão ambiental não podem prescindir da economia ecológica.

\section{Notas}

I Isso não é surpreendente, já que a própria Sociedade Internacional de Economia Ecológica foi estabelecida em 1988 e o Jornal of Ecological Economics, no ano seguinte. Embora estudos pioneiros de Ostwald e Soddy (separadamente), dentre outros, buscassem associar a termodinâmica à economia no início do século $\mathrm{XX}$, foi apenas durante a segunda metade daquele século que essa linha de pensamento se estabeleceu e institucionalizou um novo campo de pesquisa (Røpke, 2004).

2 Segundo a Teoria dos Jogos existem jogos em que é possível que todos os jogadores (agentes) terminem lucrando ("win-win"). No nosso caso, essa hipótese implica que tanto a empresa quanto a sociedade saem ganhando. Mais especificamente, obtemos tanto uma redução dos danos socioambientais por unidade de produção quanto, simultaneamente, uma elevação dos lucros. Tal dinâmica é frequentemente descrita como "ecoeficiência", isto é, eficiência econômica e ecológica. Para uma excepcional crítica ao uso da "hipótese win-win" pela gestão ambiental, ver "Quo Vadis, Environmental Management?” (Müller-Christ, 2011, cap.2).

3 Podemos definir entropia como uma medida de energia não disponível num sistema termodinâmico. Por não disponível, indica-se que essa energia não pode ser usada para realizar trabalho. Por exemplo, ao usarmos qualquer tipo de combustível fóssil, não reduzimos a sua energia química, mas sim a transformamos de energia disponível em calor e cinzas, isto é, em energia não disponível. Essa transformação pode ser descrita de outra forma: "Energia livre [disponível] implica em alguma estrutura ordenada... Energia não disponível é energia dissipada em desordem... Por isto a entropia é também definida como uma medida de desordem" (Georgescu-Roegen, 1993, p.77). A economia ecológica, como uma visão interdisciplinar da ciência, se utiliza da ideia de migração de conceito, assunto relevante em estudos atuais de Filosofia de Ciência

4 A síndrome do aparelho de barbear pode ser resumida da seguinte forma: fazer a barba mais rapidamente para ter mais tempo para produzir uma máquina de barbear mais 
rápida, para ter mais tempo para produzir uma máquina de barbear ainda mais rápida etc. ad infinitum.

5 Embora houvesse divergências entre Georgescu-Roegen e Boulding em relação ao conceito de entropia, a congruência entre o trabalho desses dois pensadores é evidente. A divergência mais aguda se dá em relação ao fato de Boulding defender a possibilidade de um sistema fechado para matéria, sem a sua dissipação e movido por energia solar. Tal diferença torna a visão de Boulding (potencialmente) menos trágica do que a de Georgescu-Roegen (ver Cechin \& Eli da Veiga, 2010; Cleveland, 1999; e Fuks, 1992, 1994).

6 Nesse texto, Boulding parece elaborar um embrião do conceito de aldeia global desenvolvido na mesma época por MacLuhan.

7 No original: "it may therefore be that... in a thousand years...our descendants will inhabit in an exhausted and ravaged earth. Man will then be pushed back into a low-level society” (ibidem, p.142).

8 Ver Boulding (1993, p.298). Na realidade, a Terra é um sistema aberto, trocando energia e matéria (por exemplo, meteoros) com o restante do universo. Entretanto, parte-se do pressuposto de que qualquer troca eventual de matéria com o resto do universo é negligenciável, o que faz sentido para aqueles que se voltam para o estudo da relação entre a econosfera e a biosfera. Ver também Pearce \& Tuner (1994, cap.2 "A economia circular"). A cidade de Kalundbork, na Dinamarca, estabeleceu tal sistema circular, um dos projetos mais renomados de Ecologia Industrial (ver www. symbiosis.dk/en).

9 Ver em particular o capítulo 3 "From empty-world economics to full-world economics” de Constanza et al. (1997, 1991) (Cechin \& Eli da Veiga, 2010.

10 Sustentabilidade fraca, frequentemente associada a economia padrão, percebe os capitais manufaturado e natural como sendo, fundamentalmente, substitutos. Consequentemente, não haveria necessidade de preservar o capital natural num certo patamar, mas sim manter constante o somatório dos dois tipos de capital. Teoricamente, o capital natural poderia se reduzir a uma quantidade infinitesimal, contanto que o substituíssemos por suficiente quantidade de capital manufaturado (Hartwick rule) (ver Solow, 1974; Ayres et al., 1998).

11 Daly (1990b) utiliza a metáfora de um barco com uma linha Plimsoll para ilustrar o fato de que eficiência alocativa não implica, necessariamente, escala sustentável. A linha Plimsoll é usada para marcar o máximo de carga que um barco pode suportar, isto é, a sua "capacidade de suporte". Na metáfora de Daly, temos um barco bem equilibrado, mas com a linha Plimsoll encoberta pelo mar, ou seja, afundando em razão do peso excessivo.

12 Essa é a posição de Elkington (1997, p.28 e p.38): “O problema é que mesmo a maior das corporações globais detém pouco controle sobre elementos chaves da agenda de sustentabilidade"; "Raciocínio Sistêmico indica que sustentabilidade não pode ser definida para uma única corporação...[e sim] por um sistema econômico-social-ecológico completo, e não para seus componentes". Cabe mencionar que, ao contrário da boa parte da literatura de gestão ambiental, Elkington ao menos reconhece a questão da escala ao citar os trabalhos de Meadows et al. (2004, p.59) e, en passant, de Boulding e Ehrlich. Por fim, Elkington (1997, p.88) chega a sugerir que a "saúde do ecossistema global é o bottom line de última estância" the ultimate bottom line). 
13 Blackburn (2007) e Porter \& Kramer (2011) são ótimos exemplos do fetiche pela "hipótese win-win".

14 "Este é o ponto: um sistema operacional de sustentabilidade é apenas boa gestão (ibidem, p.35). No seu capítulo 3, “The Value of Sustainability: Why Bother?”, Blackburn (2007) passa cerca de noventa páginas "provando" que a implementação de um SGA é benéfica para as empresas. Segundo o autor, aquelas que não seguirem esse caminho estarão abdicando de grandes fontes de lucro e arriscando ser ultrapassadas por rivais mais sustentáveis.

15 O World Business Council for Sustainable Development (WBCSD, 2008) reconhece essa tendência: "Os atuais padrões de consumo globais são insustentáveis. Com base nos fatos e tendências..., está se tornando evidente que os ganhos de eficiência e os avanços tecnológicos por si só não serão suficientes para levar o consumo global a um nível sustentável; também serão requeridas mudanças nos estilos de vida dos consumidores, incluindo as maneiras pelas quais os consumidores escolhem e usam produtos e serviços".

16 De acordo com Boulding (1993), o "conjunto mundo" é um conjunto que inclui todos os objetos que podemos identificar, enquanto a econosfera é um de seus subconjuntos que inclui, em qualquer dado momento, o "estoque total de capital, i.e., todos os objetos, pessoas, organizações, etc., que são de interesse do ponto-de-vista do sistema de trocas".

17 Tendo em vista os problemas citados, torna-se possível uma interpretação histórica khuniana do surgimento da economia ecológica com base no conceito de paradigma (Khun, 1970). Diante das consequências do crescimento da econosfera, surgiu uma série de problemas que o paradigma da economia padrão não conseguia explicar satisfatoriamente, dando margem ao surgimento de novos paradigmas. Um paradigma é uma visão de mundo, um conjunto de eixos referenciais básicos, que definem quais problemas são legítimos e quais soluções são adequadas. Há ainda a posição defendida por Tietenberg (2006, p.7), de que é possível pensar na complementariedade entre os dois paradigmas, "o que não significa aceitação completa. Diferenças significativas existem não apenas entre os dois campos, mas também internamente neles”.

\section{Referências}

ARROW, K. et al. Are we consuming too much? Journal of Economic Perspectives, v.18, n.1, p.147-72, 2004.

AYRES, R. U.; NAIR, I. Thermodynamics and economics. Physics Today, p.62-71, Nov. 1984.

AYRES, R. U. et al. Viewpoint: weak versus strong sustainability. Tinbergen Institute Discussion Papers, p.98-103/3, 1998.

BLACKBURN, W. R. The sustainability handbook: the complete management guide to achieving social, economic and environmental responsibility. Washington, DC: Environmental Law Institute, 2007.

BOUlDING, K. E. The meaning of the Twentieth Century. New York: Harper and Row, 1964.

The economics of the coming spaceship earth. In: DALY, H. E.; TOWN- 
SEND, K. N. Valuing the Earth: economics, ecology, ethics. Cambridge MA: The MIT Press, 1993. p.297-309.

CECHIN, A.; ELI DA VEIGA, J. O fundamento central da economia ecológica. In: MAY, P. (Ed.) Economia do meio ambiente: teoria e prática. 2.ed. Rio de Janeiro: Elsevier, 2010. p.33-48.

CLEVELAND, C. J. Biophysical economics: from physiocracy to ecological economics and industrial ecology in bioeconomics and sustainability: essays in honor of Nicholas Georgescu-Röegen. J. Gowdy and K. Mayumi (Ed.). London: Edward Elgar Publishing, 1999. p.125-54.

CONSTANZA, R. et al. Goals, agenda, and policy recommendations for ecological economics. In: COSTANZA, R. (Ed.) Ecological economics: the science and management of sustainability. New York: Columbia University Press, 1991. p.1-20.

Three general policies to achieve sustainability. In: JANSSON, A. M. et al. (Ed.) Investing in natural capital: the ecological economics approach to sustainability. Washington DC: Island Press, 1994. p.392-407.

An introduction to ecological economics. Boca Raton: St. Lucie Press, 1997.

COBB, J.; DALY, H. For the common good: redirecting the economy toward the community, the environment and a sustainable future. Boston: Beacon Press, 1990.

DALY, H. E. Toward some operational principles of sustainable development. Ecological Economics, v.2, p.1-6, 1990a.

Allocation, distribution, and scale: towards an economics that is efficient, just and sustainable. Journal of Ecological Economics, v.6, p.185-93, 1990 b.

DALY, H. E. et al. Are we consuming too much - For what? Conservation Biology, v.21, n.5, p.1359-62, 2007.

ELKINGTON, J. Cannibals with Forks: the Triple Bottom Line of 21 st Century Business. Oxford: Capstone Publishing, 1997.

FUKS, M. Observações preliminares sobre a introdução do conceito de entropia na ciência econômica. Rio de Janeiro, 1992. Dissertação (Mestrado em Economia) - Escola de Pós-Graduação em Economia, Fundação Getulio Vargas.

Indeterminação entrópica na economia: a exaustão de recursos naturais. $R e$ vista Brasileira de Economia, v.48, n.2, p.223-9, 1994.

GEORGESCU-ROEGEN, N. The Entropy Law and the economic process. Cambridge MA: Harvard University Press, 1971.

The Entropy Law \& the economic problem. In: DALY, H. E.; TOWNSEND,

K. N. Valuing the Earth: economics, ecology, ethics. Massachusetts: The MIT Press Cambridge, 1993a.pp 75-88

Selections from energy and economic myths. In: Valuing the Earth: economics, ecology, ethics. Cambridge MA: The MIT Press, 1993b. p.90-112.

KHUN, T. The structure of scientific revolutions. 2.ed. Chicago: University of Chicago Press, 1970.

MEADOWS, D. et al. Limits to growth: the 30 year update. White River Junction, VT: Chelsea Green Publishing Company, 2004. 
MÜLLER-CHRIST, G. Sustainable management: coping with the dilemmas of resource-oriented management. S. 1.: s. n., Springer, 2011.

PEARCE, D.; TURNER, R. K. Economics of natural resources and the environment. 3.ed. Baltimore MA: Johns Hopkins University Press, 1994.

PORTER, M. E.; KRAMER, M. R. Creating shared value. Harvard Business Review, v.89, Issue 1/2, p.62-77, Jan./Feb. 2011.

RØPKE, I. The early history of modern ecological economics. Journal of Ecological Economics, v.50, p.293-314, 2004.

SOLOW, R. M. Intergenerational equity and exhaustible resources. Review of Economic Studies, Symposium, p.29-46, 1974.

TIETENERG, T. Environmental and natural resource economics. 7.ed. New York: Pearson Addison Wesley Publisher, 2006.

VIEDERMAN, S. Public policy: challenge to ecological economics. In: JANSSON, A. M. et al. (Ed.) Investing in natural capital: the ecological economics approach to sustainability. Washington DC: Island Press, 1994.

WACKERNAGEL, M. Ecological footprint. In: Encyclopedia of Earth, 2008. Disponível em: <http://www.eoearth.org/article/Ecological_footprint>.

WORLD BUSINESS COUNCIL FOR SUSTAINABLE DEVELOPMENT. Sustainable Consumption Facts and Trends - From a Business Perspective. Novembro, 2008. Disponível em: <http://www.wbcsd.org/Pages/EDocument/EDocumentDetails.aspx? I $\mathrm{D}=142 \&$ NoSearchContextKey=true $>$.

RESUMO - Este estudo ressalta a ausência de conhecimento sobre a economia ecológica por parte do crescente número de profissionais formados em Gestão Ambiental. O autor realiza uma síntese dos princípios e fundamentos da economia ecológica, especialmente por meio das ideias de dois dos seus principais pensadores (Georgescu-Röegen e Boulding) e indica porque conhecer as ideias principais dessa escola de pensamento é fundamental para profissionais de Gestão Ambiental. Argumenta-se que esses profissionais não podem prescindir da economia ecológica, sob pena de caírem na ilusão do mito da hipótese win-win e terem uma visão incompleta das dificuldades de estabelecermos uma sociedade sustentável.

PALAVRA-CHAVE: Economia ecológica, Sustentabilidade, Gestão ambiental, Paradigma.

ABSTRACT - This study draws attention to lack of knowledge regarding Ecological Economics amongst the growing number of professionals graduating in the field of Environmental Management. The author offers a synthesis of the main principles of Ecological Economics, with particular focus on two of its main thinkers (N. Georgescu-Röegen e K. E. Boulding) and indicates why such knowledge is of fundamental impor- 
tance for Environmental Management. The paper argues that environmental managers cannot ignore Ecological Economics; else they may fall prey to the myth of the win-win hypothesis and thus have an incomplete perception of the difficulties involved in establishing a sustainable society.

KErWORDS: Ecological economics, Sustainability, Business administration, Other.

Maurício Fuks é Ph.D em Geografia pela Boston University e professor na área de Meio Ambiente do Mestrado de Economia Empresarial da Universidade Cândido Mendes, Rio de Janeiro. O autor agradece o apoio dos professores Saul Fuks, José Eli da Veiga, Amir Geiger e de Amir Harif. Quaisquer erros e omissões remanescentes são de exclusiva responsabilidade do autor. @-mauriciofuks@gmail.com

Recebido 12.12.2011 e aceito em 21.12.2011. 
